nancy occurred, and some "goodnatured friend or another" (School for Scandal) advised her to have a midwife, who promised her a living child at the full period! This was something, and naturally filled the poor ignorant woman and her friends with a degree of confidence. I heard what was to be done, and guessed pretty correctly the result, which was terrible ! For fifty hours the poor wretched creature was in strong labour, and I heard that the uterine contractions were fearful. I was sent for hurriedly, and found the woman dead; the womb had yielded, and the full-sized foetus I found was cast amidst the intestines. Nothing else could have been expected, and the midwife never after practised here; but where she went, I know not. Heaven knows that the best informed practitioner, and whose experience has been extensive, is frequently perplexed to know what to do in difficult cases of parturition. His anatomical knowledge, although it gives him confidence, yet makes him cautious in dealing with his patients. The ignorant pretender, however, rushes headlong onward, and the "finis coronat opus" usually is -death! More anon.

October 7,1844 .

\section{ON ALBUMINURIA; ITS EXISTENCE DURING PUER- PERAL CONVULSIONS ; ITS PATHOLOGY.}

\section{By G. Ross, Esq., Surgeon, Kennington.}

I PERCEIVE by a recent Number of The LANCET, that Dr. Lever has lately published some interesting observations on the co-existence of albuminuria and puerperal convulsions. I beg to inquire of that gentleman, through your columns-First, whether, and for how long a period, albumen was discoverable in the urine prior to the convulsions?-Secondly, whether in all, or in how many, of these cases, edema existed; and what was the particular state of the skin? Thirdly, whether disease of the heart was detected in any of these cases?

I am sensible of putting questions that may not have occurred to the mind of the observer at the time of treating his cases; but until these questions are put and answered, it appears to me that the connexion of albuminuria with puerperal convulsions must remain obscured.

I have already published my own conviction, derived from observation, that albuminuria is, in nearly all cases, dependent on disorder of the functions of the skin; and $I$ apprehend that the conditions of albuminuria during puerperal convulsions will tend to illustrate and establish this position. For example: in Mr. Crisp's case of puerperal convulsions attended with albuminuria, described before the Medical Society, and reported in last week's LANCET, " an cedematous condition of the face and upper extremities" is expressly noticed. Was there not also, a fortzori, disease of heart? In another case, recorded by Dr. Bree, (LANCET, No. 9, vol. i. 1844,) the patient is described as being " generally cedematons." (Disease of heart ?*)

These remarks are intended to be merely suggestive, and to direct inquiries to the general principle that may lie at the bottom of these various manifestations of albuminuria. It does not appear that albuminuria is an essential symptom of puerperal convulsions, for Dr. Lever himself, on the authority of Drs. Waller and Ramsbotham, has stated two instances of this dissociation. Albuminuria, therefore, although a frequent symptom, is simply a coincidence.

Now, as albuminuria is commonly an effect of disease of the hèart, and as such disease may exist without inducing albuminuria as a necessary consequence, it behoves us to inquire what share disease of the heart may have in the causation of puerperal convulsions. Supposing the heart to be diseased, no one would be surprised that the laborious efforts of parturition should induce general convulsions, or even that the pressure of the gravid uterus upon the great vessels should give rise to the same effects.

If any practitioner can give me information on the points herein contained, I shall be obliged.

Note.-At the last meeting of the London Medical Society, Dr. Williams referred to my views of albuminuria, and stated positively that they were not correct. Although no dialectician myself, yet I have seen enough of the adroitness of practised debating to be aware that nothing is so easy as to seize upon a few of the salient points of any complicated argument, and by a little sharpening of the wit, convert them into powerful weapons of offence. Dr. Williams seems to have given my views only a partial consideration, or he could not so hastily and dogmatically have pronounced his dissent.

Dr. Williams said I had affirmed " that the presence of

* The case detailed by Mr. Rose, of Swafrham, (LANcer, No. 21, vol. i 1843-1844,) was also " universally anasarcous." These are the only case that, at present, I have the opportunity of referring to, but they remarkably illustrate my views of albuminuria. albumen in the urine was attended by a dry state of the skin:" and again, the doctor says, "that albumen was often found in the urine when the skin was perfectly moist"-a statement in which Dr. T. Thompson and Dr. Rees coincided.

My statement runs thus:- " When the skin was dry, and the anasarca mounted to the hips, coagulable urine would be certainly found," \&c.; and this position I will maintain at any time and place. I have never said that mere moisture of the skin was a preventive of albuminuria. I, as well as other gentlemen, have seen a certain amount of albumen in the urine when the upper part of the body has been bathed in perspiration; but when the effusion under the skin has covered a greater extent, and the functions of this organ have been, consequently, more interfered with, I have found the amount of albumen proportionably to increase. I have not yet been so unphilosophic as to make an unconditional statement respecting a disease so full of contrarieties. I take it for granted that when the cellular tissue is loaded with serum, the functions of the skin will be arrested to that extent, and if any gentleman can shew me a case to the contrary, $I$ will, with pleasure, journey ten miles to see it.

Let the objectors to this doctrine adduce satisfactory cases against my positions, and I will abandon them without a regret. My aim is, the development of facts and the establishment of truth.

Meanwhile, as this is a most important doctrine, and it might be prejudiced by dogmatic remarks at an influential debating society, I will at any time state my views personally to the members of the society, and be ready to meet any objections that may be offered. This demand is made in the spirit of fair play. Will they refuse it?

October, 1844

\section{THE LANCET.}

\section{LONDON : SATURDAY, OCT. 26, 1844.}

THE Government has no right to require that the subject of MeDical REForm shall be argued, or considered, as an abstract question.

Whilst introducing THE BILL to the notice of the House of Commons, the HoMe SeCretary appeared studiously to refrain from noticing the protection which the law affords to the members of other professions in this country; and it did not seem to be convenient to him to refer to any of the advantages which had sprung out of the penal provisions of the Statute of 1815-the ApothecARIEs' Acr. In pursuing this discussion, we shall not adopt the course which the Government has marked out. (In referring to the "Grovernment" and the "Home Secretary," of course we allude to them as identical authorities.) But whatever aids the cause of medical polity can derive from collateral and. incidental illustrations, we are determined that it shall receive,so far, that is, as it may be in our capacity to supply them.

We have ascertained, with feelings of great satisfaction, that the clauses which we quoted in the last LANCET from the ATtORNIES AND Solicitors' Acr, (passed into a law in the Session of 1843, ) have been read by medical practitioners with sensations of astonishment. When the question is asked, "Ought the medical profession to receive the protection of the law?" the public may possibly infer that to no other profession has such a protection been given. But if it be indisputably demonstrated, by the specified sections of an Act of Parliament, that such a protection has been awarded to another profession, and does actually exist, the question derives immense support when such an illustration is produced in the argument on behalf of a similar protection to medicine. As we have stated, however, our medical brethren have been stricken with astonishment, on perusing the sections of the ATronnies AND Solicitors' ACT which we printed last week, (page 106.) When the Government proposition with regard to Medicine is considered, the provisions which are contained in those clauses against unqualified practitioners in the law, are, indeed, amply sufficient to excite in the minds of the medical practitioners of this country the strongest feelings of indignation. They may, indeed, well feel indignant at being 